\title{
Evaluating Provitamin A Carotenoids and Polar Metabolite Compositions during the Ripening Stages of the Agung Semeru Banana (Musa paradisiaca L. AAB)
}

\author{
Rosita D. Chandra, ${ }^{1}$ Chandra A. Siswanti, ${ }^{1}$ Monika N. U. Prihastyanti, ${ }^{1}$ Heriyanto, ${ }^{1,2}$ \\ Leenawaty Limantara, ${ }^{3}$ and Tatas H. P. Brotosudarmo $\mathbb{D}^{1}$ \\ ${ }^{1}$ Ma Chung Research Center for Photosynthetic Pigments (MRCPP) and Department of Chemistry, Universitas Ma Chung, \\ Villa Puncak Tidar N01, Malang 65151, Indonesia \\ ${ }^{2}$ Faculty of Biochemistry, Biophysics and Biotechnology, Jagiellonian University, Ul. Gronostajowa 7, 30-387 Krakow, Poland \\ ${ }^{3}$ Center for Urban Studies, Universitas Pembangunan Jaya, Jl. Cendrawasih Raya B7/P, South Tangerang, 15413 Banten, Indonesia
}

Correspondence should be addressed to Tatas H. P. Brotosudarmo; tatas.brotosudarmo@machung.ac.id

Received 7 January 2020; Accepted 20 April 2020; Published 12 May 2020

Academic Editor: Amarat (Amy) Simonne

Copyright (c) 2020 Rosita D. Chandra et al. This is an open access article distributed under the Creative Commons Attribution License, which permits unrestricted use, distribution, and reproduction in any medium, provided the original work is properly cited.

\begin{abstract}
Banana cultivars that are rich in provitamin A carotenoids and other nutrients may offer a potential food source to help alleviate vitamin A deficiencies, particularly in developing countries. The local plantain type banana, Agung Semeru (Musa paradisiaca L.), was investigated, in order to analyse the changes in the compositions of the provitamin A carotenoids and metabolite compounds, including the amino acids, organic acids, and sugars, during the ripening stage as this banana is widely processed for food products in either the unripe, ripe, or overripe stages. The bananas that had reached the desired ripening stages were subjected to highperformance liquid chromatography (HPLC) analysis, and the results indicated that the total provitamin A carotenoid concentrations ranged between $4748.83 \mu \mathrm{g} / 100 \mathrm{~g}$ dry weight $(\mathrm{dw})$ and $7330.40 \mu \mathrm{g} / 100 \mathrm{~g} \mathrm{dw}$, with the highest level of vitamin A activity at $457.33 \pm 5.18 \mu \mathrm{g}$ retinol activity equivalents (RAE)/100 g dw. Compared to the Cavendish variety, which is consumed worldwide, the Agung Semeru banana had vitamin A activity that was 40 to 90 times higher, dependent on the stage of ripening. The breakdown of the starch during the ripening stages resulted in an increase of its sugar compounds, such as sucrose, fructose, and glucose, as well as its dominant organic acids, such as malic acid, oxalic acid, and citric acid, which were observed using gas chromatography-mass spectrometry (GC-MS) during the ripening stages. The findings of this study show that the Agung Semeru banana is a promising fruit that could be widely produced as a nutritional and energy food resource, due to its high levels of vitamin A activity and sugars.
\end{abstract}

\section{Introduction}

Nutritional deficiencies and malnutrition are still global problems, especially for the poor and the majority of developing countries, including Indonesia, leading to health problems such as skin diseases, defective bone growth, dementia, and increased mortality [1-4]. In Indonesia, vitamin A deficiency (VAD) is a nutritional deficiency that is considered mild and not a public health problem, as it impacts less than $10 \%$ of the population [5]. However, this must be interpreted with caution as the prevalence of VAD may differ from year to year [5]. In 2001, as an example year, $18 \%$ of mothers and $54 \%$ of infants were found to be VAD in Indonesia [3]. According to Atmarita [4], there are two categories of nutritional problems: (1) insufficient food intake and (2) excessive or unbalanced food intake. In Indonesia, the first category is the main reason for nutritional deficiencies, including VAD. Nevertheless, positive health behaviours and better eating habits could play an important role in improving the nutritional status. Consuming fruits or vegetables rich in provitamin A carotenoids is one alternative that can be employed to reduce the number of vitamin A deficiencies in Indonesia. 
Bananas are a tropical fruit that grows abundantly in all regions of Indonesia and can thus be easily be obtained. Besides containing nutritional compounds including carbohydrates, proteins, sugars, and minerals, bananas also provide provitamin $\mathrm{A}$ carotenoids such as $\alpha$-carotene and $\beta$ carotene that can be converted into vitamin $\mathrm{A}$ in the human body [6]. The vitamin A activity of carotenoids is indicated by retinol activity equivalents (RAE), and as described by the Institute of Medicine (U.S.), the conversion factor for $\beta$-carotene is 12 , i.e., $1 \mu \mathrm{g} \mathrm{RAE}$ is equal to $12 \mu \mathrm{g} \beta$-carotene or $24 \mu \mathrm{g}$ of other provitamin A carotenoids, such as $\alpha$-carotene and $\beta$-cryptoxanthin [7]. Therefore, bananas are considered a fruit that when regularly consumed could help to combat VAD, particularly in Indonesia.

Banana cultivars that are rich in provitamin A carotenoids may be a food source that could help alleviate VAD [8]. The most marketed banana cultivars, Cavendish type, contain low levels of provitamin A carotenoids, ranging from 21 to $290 \mu \mathrm{g} \beta$-carotene/100 g dry weight (dw) [8-11]. An attempt to increase the level of provitamin A to $20 \mu \mathrm{g} / \mathrm{g}$ of $\beta$-carotene has been achieved in transgenic Cavendish bananas [12]. In Southeast Asia, there are 149 local cultivars of edible bananas [13], and some have an average concentration of $\beta$-carotene that ranges from 230 to $1370 \mu \mathrm{g} / 100 \mathrm{~g} \mathrm{dw}$ $[8,9]$. One variety of banana that is typical to Indonesia and of interest for further investigations is the Agung Semeru (Musa paradisiaca L. AAB plantain); as to the best of our knowledge, there have been no previous studies conducted to examine the content of the provitamin A carotenoids in this banana. Agung Semeru grows well at 450-650 m above sea level. The characteristic of this plantain include the colour of its pseudostem (light red), the number of suckers per cluster (only 1-2 suckers per cluster), the size of the fingers (33$36 \mathrm{~cm}$ long and $19 \mathrm{~cm}$ around), the number of hands per bunch (only 1-2 hands per bunch), and a weight of $\sim 10$ $20 \mathrm{~kg} /$ bunch $[14,15]$. It has been cultivated only in East Java, Indonesia, especially in the Lumajang regency, on more than 553 hectares of land, with an average production of 28000 tons per year. The fruits have a long storage period of 3-4 weeks after harvesting, as the flesh can still be consumed although the peels do turn black $[16,17]$.

The Agung Semeru bananas are usually harvested at the mature green stage, as it is widely processed for food products in either the unripe, ripe, or overripe stages. Therefore, it is necessary to investigate the compositions of the provitamin A carotenoids during the different ripening stages. The peel colours are often used as the major indicator to determine fruit ripeness [18]. Several studies have focused on the carotenoid accumulations and chlorophyll degradation mechanisms in the peel of banana fruits during postharvest ripening $[19,20]$. However, the natural ripening is a combination of physiological, biochemical, and molecular processes that lead to changes in the colour, sugar content, acidity, flavour, aroma, and carotenoid contents and compositions [21-26], impacting the quality of the banana. Thus, besides the importance to determine the amount and availability of the provitamin A carotenoids, other metabolite compounds from the early to the final stage of ripening should be evaluated to determine the quality of the banana and further improve human nutritional status. Hence, the aim of this study was to analyse the changes in the compositions of the provitamin A carotenoids and metabolite compounds, including the amino acids, organic acids, and sugars during the ripening stages of the Agung Semeru (Musa paradisiaca L.) plantain.

\section{Materials and Methods}

2.1. Plant Material and Preparation. Agung Semeru (Musa paradisiaca L. ABB group) plantain bunches from the Senduro banana plantation, Lumajang regency, East Java, were collected from a single batch harvest. Each bunch of the Agung Semeru plantains contained 10-14 fingers and did not have a hand. The samples were harvested during the rainy season and were selected when the fruits of the identified bunches were mature (deep green, full, and rounded) and standardized according to the size of the fruit, absence of physiological defects, and visual infections. The fruit samples were allowed to ripen naturally in a well-aerated and well-shaded room at ambient temperatures $\left(25 \pm 2^{\circ} \mathrm{C}\right)$. The ripening stages of the bananas were observed on the basis of the peel colour (Figure 1(a)): 1=green; 2 =green with a trace of yellow; $3=$ more green than yellow; $4=$ more yellow than green; $5=$ only green tips remaining; $6=$ all yellow; and $7=$ yellow flecked with brown [27]. Prior to the analysis, one finger from three different bunches that had reached the desired ripening stage was randomly detached for analysis in triplicate, by cutting with a knife at the base part of the fruit, without damaging the other fingers; then, they were cleaned and cut into three parts. The rest of the fingers were left attached to the bunch to ripen naturally in the same room conditions.

2.2. Carotenoid Extraction and HPLC Analysis. All extractions were carried out in triplicate according to previously reported protocols [28] with modifications, specifically for the analysis of the banana tissues. Fresh banana flesh aliquots $(0.2 \mathrm{~g})$ were homogenized for $5 \mathrm{~min}$ at maximum speeds on a vortex (IKA, Staufen, Germany) in $1.0 \mathrm{~mL}$ ice-cooled extraction solvent. The extraction solvent consisted of EtOH and $n$ hexane $(4: 3, v / v)$. The extract was kept cool on ice, and the extraction was carried out in a dark room. Following centrifugation at $5000 \mathrm{rpm}$ for $1 \mathrm{~min}$ at $5^{\circ} \mathrm{C}$, the supernatant was evaporated using a rotary evaporator (Heidolph, Schwabach, Germany). The residues were then redissolved in $1 \mathrm{~mL}$ acetone and then filtered using a filter membrane (PTFE, $0.2 \mu \mathrm{m})$ prior to HPLC analysis.

Twenty $\mu \mathrm{L}$ of each sample was used for the determination of the carotenoid content, following the method of Kurniawan et al. [29], using separation with a Shimadzu highperformance liquid chromatograph (HPLC) on a YMC carotenoid C-30 reversed-phase (Wilmington, MA, USA) column $(150 \times 4.6 \mathrm{~mm}$ I.D. $)$, equipped with a guard column and photodiode array detector, using the elution gradient program of $\mathrm{H}_{2} \mathrm{O}$ : methanol : methyl tert-butyl ether (MTBE) $(4: 81: 15, v / v / v)$ at $0 \mathrm{~min}$ and $\mathrm{H}_{2} \mathrm{O}:$ methanol:MTBE $(4: 6: 90, v / v / v)$ at $70 \mathrm{~min}$, with a flow rate of $1 \mathrm{~mL} / \mathrm{min}$ at $30^{\circ} \mathrm{C}$. The standard curves of the pigments, lutein, $\alpha$-carotene 


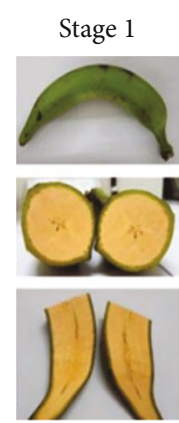

Day 0
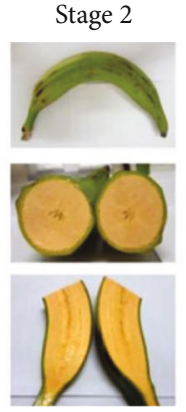

Day 2

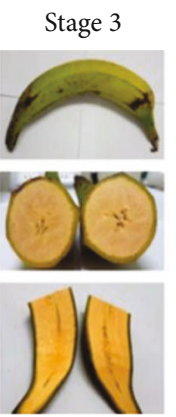

Day 6

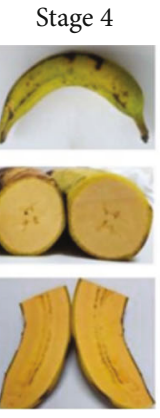

Day 7

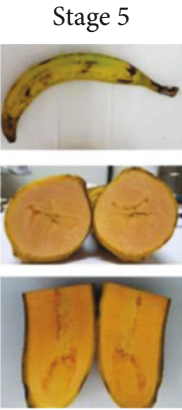

Day 8

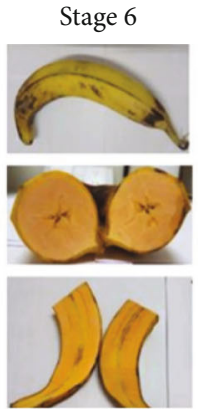

Day 10

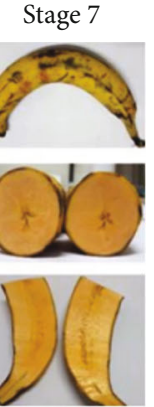

Day 11

(a)
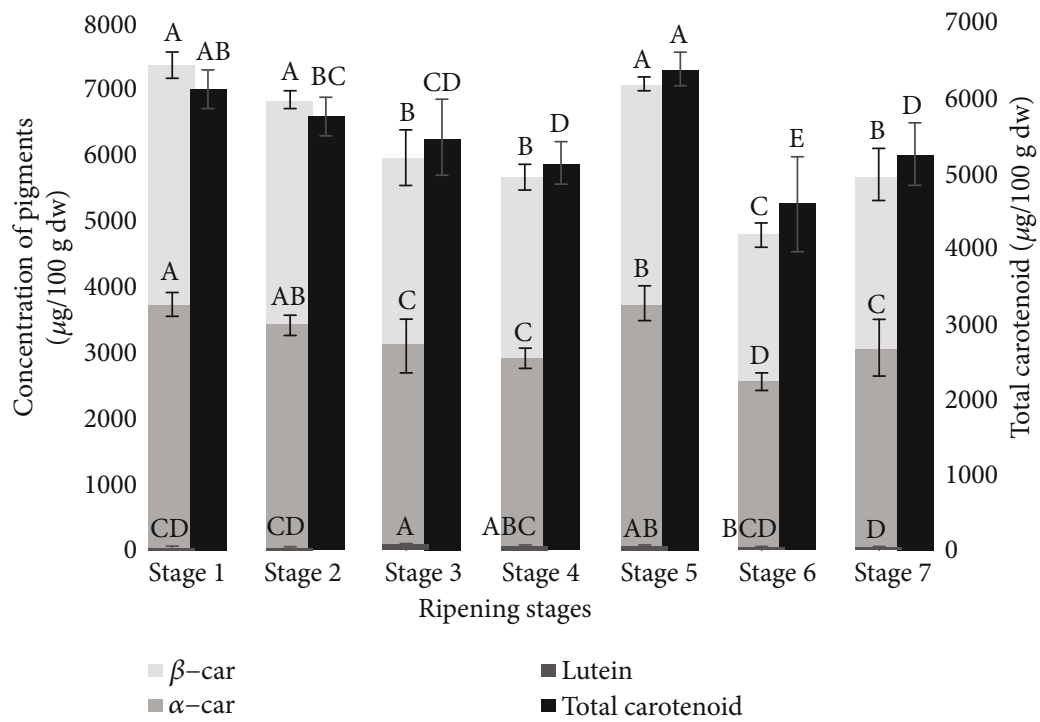

(b)

Figure 1: Changes in the carotenoids of Agung Semeru plantains during development. (a) Changes in the fruit colour during postharvest ripening. (b) Changes in the carotenoid content and composition of the fruit flesh during postharvest ripening, obtained from analysis using HPLC ( $\beta$-car, $\alpha$-car, and lutein) and spectrophotometry UV-Vis (total carotenoid). Different lowercase letters indicate significant differences among the ripening stages $(p<0.05)$.

( $\alpha$-car), and $\beta$-carotene $(\beta$-car), were obtained by using the standard pigment manufactured by NATChrom (Malang, Indonesia). The linear equations were used to determine the concentrations of the lutein $\left(y=305.8 x-0.6335, R^{2}=\right.$ $0.9999), \alpha$-car $\left(y=232.04 x+47.906, R^{2}=0.995\right)$, and $\beta$-car $\left(y=206.57 x+74.953, R^{2}=0.9982\right)$ (where $y$ is the peak area and $x$ is the concentration of the determined pigment) in $\mu \mathrm{g} / \mathrm{mL}$, at their maximum absorption wavelengths $\left(\lambda_{\max }\right)$ of 445,445 , and $450 \mathrm{~nm}$, respectively. The rest of the sample was then measured using the pigment absorption spectrum with the spectrophotometer (UV-1700, Shimadzu) for determination of the total carotenoids.

2.3. Determination of Total Carotenoid and Vitamin A Activity. Total carotenoids were measured using the following equation provided by Gross [30]:

$$
\frac{\mu \text { g carotenoid }}{g}=\frac{A \times V \times 10^{6}}{A_{1 \mathrm{~cm}}^{1 \%} \times 100 \times G},
$$

where $A$ is the maximum absorbance, $V$ is the volume $(\mathrm{mL})$, $G$ is the weight of sample $(\mathrm{g})$, and $A_{1 \mathrm{~cm}}^{1 \%}=2500$ for a specific absorbance extinction of a mixture of carotenoids in acetone.

The values obtained from Equation (1) were on a fresh weight ( $\mathrm{fw}$ ) basis, and the moisture content was determined using a Shimadzu MOC63u moisture analyser. Both results had to be converted into dry weight ( $\mathrm{dw}$ ) as follows:

$$
\begin{aligned}
\text { Total carotenoid }(\mathrm{dw})= & \text { Total carotenoid }(\mathrm{fw}) \\
& \times \frac{100}{100-\text { moisture content }(\%)} .
\end{aligned}
$$

After the measurement of the total carotenoids, the calculation of the vitamin A activity of the carotenoids in each stage of the banana was carried out by determining the concentrations of the provitamin A carotenoids, $\alpha$-car and $\beta$-car, by using each standard curve formula. After that, the conversion of the provitamin A carotenoids to the vitamin A activity in the retinol activity equivalent (RAE) was calculated by 
using the newly advised conversion factor, as described by the Institute of Medicine (U.S.), of a $12: 1$ conversion from the $\beta$-car and a $24: 1$ from the $\alpha$-car equivalents to RAE [7].

2.4. Analysis of the Composition of Amino Acids, Organic Acids, and Sugars by Gas Chromatography Coupled with Mass Spectrometry. The following method was a modification from a previously published method [31]. Bananas were frozen overnight prior to the lyophilization process (Labconco Co., USA) for $24 \mathrm{~h}$ at $-45^{\circ} \mathrm{C}$ under high vacuum conditions ( $0.04 \mathrm{mbar})$. The lyophilized fruit samples $(50 \mathrm{mg})$ from the different ripening stages were ground into fine powder, followed by extraction with $700 \mu \mathrm{L}$ methanol, with the addition of the internal standard (IS), $150 \mu \mathrm{L}$ ribitol $(0.2 \mathrm{mg} / \mathrm{mL}$ in water) [32]. After extraction for $30 \mathrm{~min}$ at $70^{\circ} \mathrm{C}$, they were vigorously mixed with $500 \mu \mathrm{L}$ water and $300 \mu \mathrm{L}$ chloroform, in order to separate the polar and nonpolar metabolites. The mixture was then subjected under centrifugation at $10000 \mathrm{rpm}$ for $5 \mathrm{~min}$. Five hundred $\mu \mathrm{L}$ of the upper phase which consisted of water/methanol was taken and dried using nitrogen gas. The residue was derivatized with $50 \mu \mathrm{L}$ $\mathrm{N}$-methylhydroxylamine hydrochloride $(20 \mathrm{mg} / \mathrm{mL}$ in pyridine) at $50^{\circ} \mathrm{C}$ for $30 \mathrm{~min}$, followed by treatment with $100 \mu \mathrm{L}$ $\mathrm{N}, \mathrm{O}$-bis(trimethylsilyl)trifluoroacetamide at $60^{\circ} \mathrm{C}$ for $30 \mathrm{~min}$. The sample volume of $0.2 \mu \mathrm{L}$ was injected into the GC column in a splitless mode.

The analysis using the GC-MS was performed on a Shimadzu QP2010 Plus instrument, operating in EI mode at $70 \mathrm{eV}$. The column used was Rtx-5MS $(30 \mathrm{~m} \times 0.25 \mathrm{~mm} \times$ $0.25 \mu \mathrm{m}$ ). Helium (GC-MS grade) was used as the carrier gas, flowing at a rate of $3 \mathrm{~mL} / \mathrm{min}$. The temperatures of the column oven and the injection were set at $40^{\circ} \mathrm{C}$ and $280^{\circ} \mathrm{C}$, respectively. The temperature program for the analysis was performed as follows: $5 \mathrm{~min}$ at $40^{\circ} \mathrm{C}$ followed by a ramp of $20^{\circ} \mathrm{C} / \mathrm{min}$ up to $180^{\circ} \mathrm{C}$, and this was held for $3 \mathrm{~min}$. The second ramp was $5^{\circ} \mathrm{C} / \mathrm{min}$ up to $280^{\circ} \mathrm{C}$ and was held for $5 \mathrm{~min}$. Meanwhile, the mass spectrum, which was recorded at 2 scans/s, was set in the scanning range, from 40 to $550 \mathrm{~m} / z$. The temperatures of the interface and the ion sources were adjusted to $280^{\circ} \mathrm{C}$ and to $230^{\circ} \mathrm{C}$, respectively.

2.5. Multivariate Data Analysis and Statistical Analysis. Means \pm SE of each pigment compound from the ripening stages were statistically assessed from three replicates by mean comparison through a Tukey test using Minitab software version 17 (Minitab, State College, PA, USA). The mean differences within a 95\% confidence interval $(p<0.05)$ were considered significant differences among the ripening stages.

Spectral data files of GC-MS were processed with the Wiley Registry library software (Wiley Registry ${ }^{T M}$ of Mass Spectral Data, 9th edition, Ringoes, New Jersey) for metabolite identification. The detected metabolite peaks were identified by the software, and the extracted compounds were aligned according to the internal standard ribitol. Peaks with a similarity index of more than $80 \%$ were used for feature identification. After review, the relative concentrations based on the peak area of the compounds were normalized into a dry weight basis (dw), according to Equation (2). For further data analysis, using $\mathrm{R}$ software version 3.4.0, a principal com- ponent analysis (PCA) was used to visualize the data in accordance with the different ripening stage samples.

\section{Results and Discussion}

3.1. Carotenoid Analysis and Its Changes during Postharvest Ripening. The ripening changes in the Agung Semeru plantains were assessed in terms of the colour of the peel and flesh and the time that it took for each stage to be observed. Figure 1(a) shows the colour changes in the fruit flesh, which tended to become more orange with time, following the colour change in the peel. Stages 3 to 7 occurred between days 6 and 11 , which was considered a rapid change. A previous study [15] determined that the storage duration of the Agung Semeru plantains was around 3 to 4 weeks postharvest, as the flesh was not too tender and still edible, although the peel colour turned dark brown and black.

The strong orange colour occurred in stage 5, and this stage contained the highest amounts of total carotenoids (Figure 1(b)). However, although the colour of the flesh at stages 6 and 7 looked like that of stage 5, the total carotenoid contents were considerably lower. Interestingly, stage 1 had the second highest total carotenoid content after stage 5 , even though the colour of the flesh still looked pale.

Besides observing the colours of the plantain, the carotenoid pigments including $\alpha$-car, $\beta$-car, and lutein, which were the main pigments in the banana, were determined and compared with the total carotenoid content. Previously, the major carotenoids identified in ripe bananas were lutein, $\alpha$-car, and $\beta$-car, detected at 445,451 , and $453 \mathrm{~nm}$ [33]. Figure 1(b) represents the total concentration of the $\alpha$-car, $\beta$-car, and lutein in each ripening stage, obtained from the calibration curve calculations, using high-performance liquid chromatography (HPLC).

For the identification of the pigments in the Agung Semeru plantains during the ripening stages, cochromatography between crude carotenoid extracts and carotenoid standards, which were lutein, $\alpha$-car, and $\beta$-car, was applied to verify the identification results. It was in relation to its spectroscopic and chromatographic properties, such as the shape of the absorption spectrum, the position of the absorption maxima $\left(\lambda_{\max }\right)$, and the retention time $\left(t_{\mathrm{R}}\right)$, compared to the reference. Figure 2 shows the chromatogram of stage 5 which was selected to represent all the ripening stages as it presented the highest amounts of total carotenoids, despite the changes in the concentrations of each pigment during the ripening stages. The HPLC separation profile contains three well-resolved compounds. The first compound, peak \# 1 eluted at a $t_{\mathrm{R}}$ of $8.3 \mathrm{~min}$, corresponds to lutein. The second and third compounds, peaks \#2 and \#3 eluted at retention times of 23.5 and $26.4 \mathrm{~min}$, correspond to $\alpha$-car and $\beta$-car, respectively.

The content of the $\alpha$-car, $\beta$-car, and lutein during the ripening stages (the data are clearly shown in Supplementary Table 1) were significantly different $(p<0.05)$, in the range of $2509.88 \pm 5.49 \mu \mathrm{g} / 100 \mathrm{~g}$ dw to $3684.79 \pm 4.51 \mu \mathrm{g} / 100 \mathrm{~g} \mathrm{dw}$ for $\alpha$-car whereas $\beta$-car ranged from $2238.94 \pm 7.79 \mu \mathrm{g} / 100 \mathrm{~g}$ $\mathrm{dw}$ to $3645.61 \pm 5.53 \mu \mathrm{g} / 100 \mathrm{~g} \mathrm{dw}$, with the highest levels of $\alpha$-car and $\beta$-car obtained in stage 1 . The ratio of the $\alpha-/ \beta$ - 


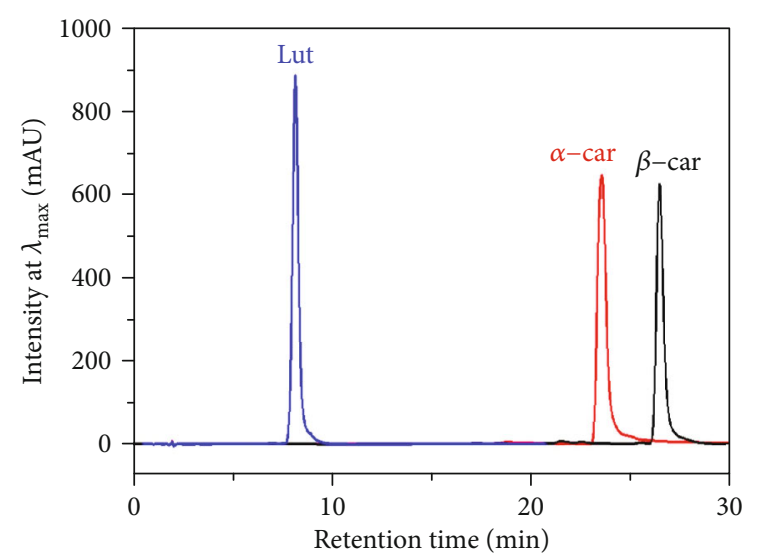

(a)

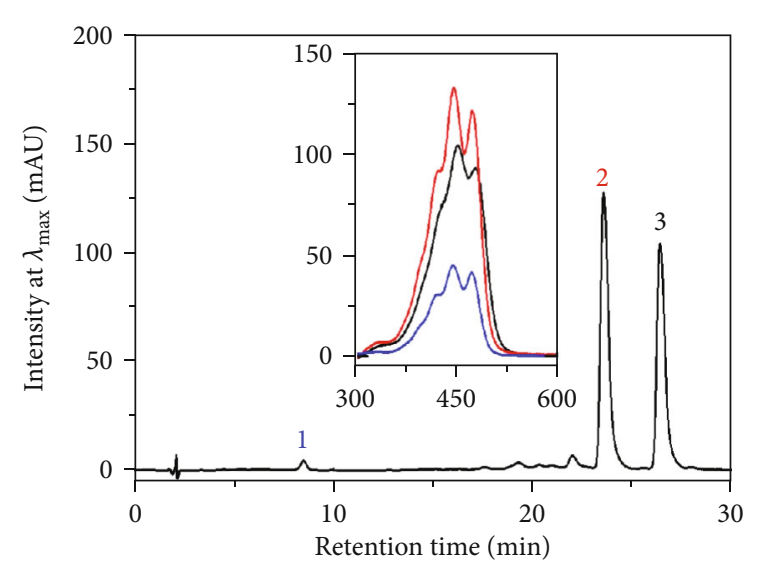

(b)

FIGURE 2: HPLC chromatogram profile of the standard lutein, i.e., $\alpha$-car and $\beta$-car (a), and the extracts of the Agung Semeru plantain fruits at ripening stage 5 (b). The inset figure is the absorption spectra of the lutein (blue), $\alpha$-car (red), and $\beta$-car (black) in the HPLC eluent.

car presented in stages 1 to 7 was $1.011,0.997,1.059,1.033$, $1.103,1.121$, and 1.157, respectively, which shows that a high ratio of $\beta$-car was rare and was only found at stage 2 , whereas the ratio of $\alpha$-car constantly increased from stage 5 , reaching its highest ratio at stage 7 . Meanwhile, the lutein which had the lowest pigment content, was presented in the range of $39.11 \pm 11.78 \mu \mathrm{g} / 100 \mathrm{~g}$ dw to $93.49 \pm 21.13 \mu \mathrm{g} / 100 \mathrm{~g}$ $\mathrm{dw}$, in which the highest amount was found in stage 3 and the lowest in stage 7 .

The concentrations of provitamin A carotenoids ( $\alpha$-car and $\beta$-car) were converted into vitamin A activity, and the retinol activity equivalents (RAE) ranged between $291.16 \pm$ $20.06 \mu \mathrm{g}$ RAE/100 $\mathrm{g} \mathrm{dw}$ and $457.33 \pm 23.71 \mu \mathrm{g}$ RAE/100 g $\mathrm{dw}$, with the highest vitamin A activity at stage 1 , but it was not significantly different from that at stage 5 (430.96 \pm $18.84 \mu \mathrm{g} \mathrm{RAE} / 100 \mathrm{~g} \mathrm{dw}$ ) (shown in Supplementary Table 1). The recommended dietary intake (RDI) values for vitamin A are $700 \mu \mathrm{g}$ RAE for females and $900 \mu \mathrm{g}$ RAE for males [34]. This suggests that by consuming 150 to $300 \mathrm{~g}$ of Agung Semeru bananas, depending on the ripening stage, the daily requirement of vitamin $A$ could be fulfilled. In other local varieties of banana (Cavendish, Candi, Berlin, Raja, and Mas) that we analysed (unpublished data), at ripening stage 7 , the vitamin A activity was $5.35 \pm 0.80 \mu \mathrm{g}$ $\mathrm{RAE} / 100 \mathrm{~g} \mathrm{dw}, 70.11 \pm 20.19 \mu \mathrm{g} \mathrm{RAE} / 100 \mathrm{~g} \mathrm{dw}, 93.66 \pm$ $12.51 \mu \mathrm{g}$ RAE$/ 100 \mathrm{~g} \mathrm{dw}, 95.13 \pm 7.77 \mu \mathrm{g} \mathrm{RAE} / 100 \mathrm{~g} \mathrm{dw}$, and $118.02 \pm 46.84 \mu \mathrm{g} \mathrm{RAE} / 100 \mathrm{~g} \mathrm{dw}$, respectively. This shows that the amount of vitamin A activity in the Agung Semeru banana was 2 to 90 times higher than that in all of these aforementioned bananas. The results also show that the Cavendish variety, which is consumed worldwide, provided the lowest amount of vitamin A activity, requiring about 14 000 to $18000 \mathrm{~kg}$ to fulfil the daily need of vitamin A. Hence, the Agung Semeru banana has promise as a fruit that may be able to fulfil our daily requirements of vitamin A.

The total concentrations of $\alpha$-car, $\beta$-car, and lutein were compared to the total carotenoid measured using a spectrophotometer, which was also determined in this study, and there was a significant difference in the results (Figure 1(b)). At the seven ripening stages, the total carotenoids ranged from
$4609.29 \pm 253.78 \mu \mathrm{g} / 100 \mathrm{~g}$ dw to $6405.03 \pm 87.37 \mu \mathrm{g} / 100 \mathrm{~g}$ $\mathrm{dw}$, with the highest amount obtained in stage 5 , but it was not significantly different from that of stage 1 . The differences or gaps in the results found between the two methods were probably caused by the presence of the minor pigments, which were detected in all the ripening stages of the banana. Those minor pigments were classified into four groups, oxidized carotene group, cis- $\alpha$-carotene group, cis- $\beta$-carotene group, and a not identified carotene group, which contributed around 4.24 to $9.56 \%$ to the total of the carotenoid pigments. In addition, the different results might be due to the more specific pigments targeted in the determination using HPLC, while in that using a spectrophotometer all the carotenoids in the plantain were calculated. Besides that, the use of the epsilon value $\left(A_{1 \mathrm{~cm}}^{1 \%}\right)$ in the total carotenoid calculation, which is not specific for one dilution solvent, may also influence the results.

3.2. Analysis of Polar Metabolites during Postharvest Ripening. Polar metabolites of the Agung Semeru plantain were subjected to GC-MS analysis, and 100 peaks were resolved, but only 27 peaks were picked for compound identification. The chosen peaks were identified based on the similarity of the retention indexes with the mass spectral libraries of the WILEY09, with similarities $\geq 85 \%$ (Supplementary Table 2). Most of the compounds were classified in the primary and secondary metabolites including sugar, organic acids, and amino acids, with multiple peaks provided by oxalic acid, fructose, glucose, and maltose. Approximately 13 peaks were identified at stages 1 and 2, 17 at stages 3 and 4 , and 16 at stages 5 to 7 (Supplementary Table 2).

A typical GC-MS chromatogram of the polar metabolite compounds of ripening stage 5 can be seen in Supplementary Figure 1, as a representative example for the Agung Semeru plantain. It was chosen as the highest levels of total carotenoids were found at this stage. The peaks shown in the chromatogram were identified in Supplementary Table 2. The classes of compounds emitted most by the plantain at ripening stage 5 were the sugars, as they completely dominated the spectra at this stage, detected at $17 \mathrm{~min}$ 


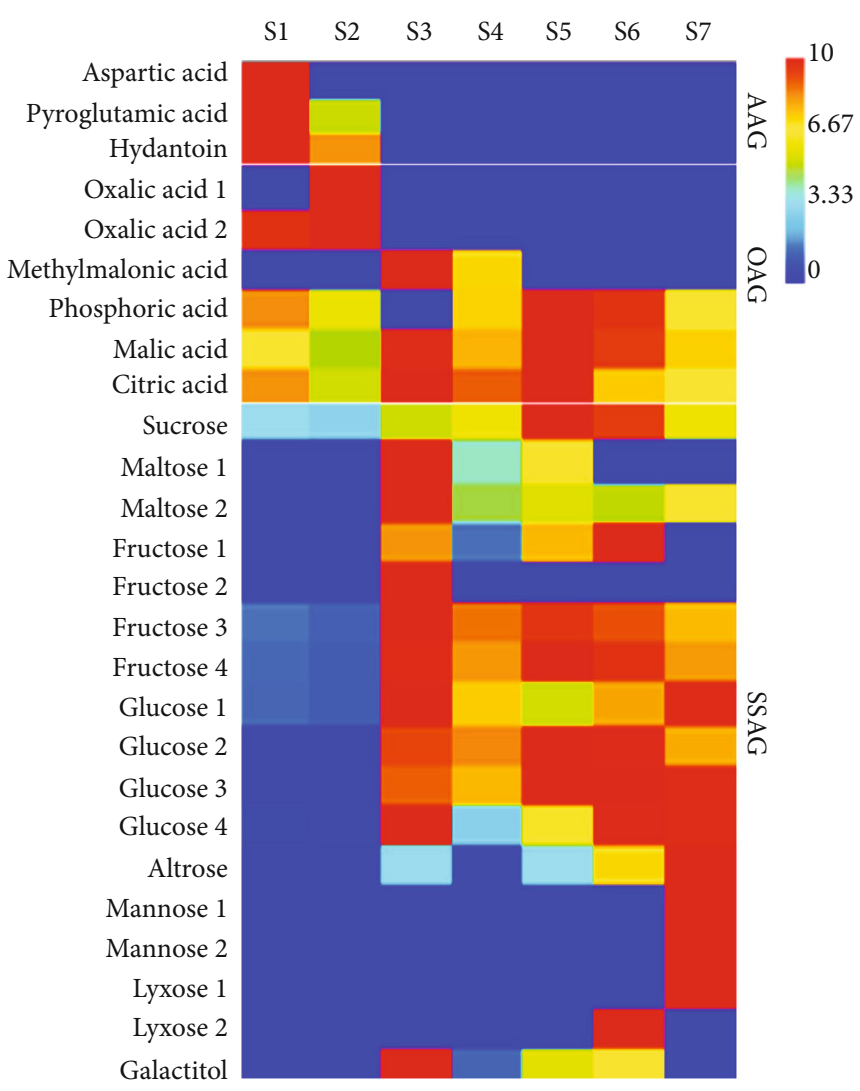

Figure 3: Polar metabolite levels, representatives of the major groups that changed during the development of the Agung Semeru plantain fruits. The amounts were based on the area of each peak which was normalized to the dry weight of each ripening stage (area/g). The ratio of the metabolite content at each ripening stage to the average metabolite content across the seven ripening stages is shown by the colour scale; the lowest ratio is in dark blue, and the highest ratio is in dark red. $A A G=$ amino acid group; $O A G=$ organic acid group; SSAG $=$ sugar and sugar alcohol group.

(peak \#10), while all the organic acids were not found in all the ripening stages. Oxalic acid was found in stages 1 and 2, while methylmalonic acid was detected in stages 3 and 4. Moreover, the malic acid and citric acid were found at all ripening stages, whereas the phosphoric acid was not presented at stage 3 .

To clearly highlight the differential distributions of the polar metabolites from the immature fruits (stage 1) to the overripe fruits (stage 7), a heat map is provided in Figure 3. Sucrose, maltose, fructose, and glucose were detected in this plantain as the major sugars. According to Arena et al. [35], the sucrose, glucose, and fructose have been found to be the most abundant carbohydrates, widely distributed in plants, with considerable variations in their ratios during the ripening stage. Maltose, fructose, and glucose began to accumulate at stage 3 and sucrose at stage 5 . Sucrose was previously found to be the predominant sugar in the green stage of the banana [36], and this is in agreement with the findings presented here. Sucrose was found at the level of $32.21 \times 10^{6}$ area/g dw at stage 1 and $29.31 \times 10^{6}$ area/g dw at stage 2 , continuing to increase by three times $\left(92.10 \times 10^{6} \mathrm{area} / \mathrm{g} \mathrm{dw}\right)$ at stage 5 and gradually decreasing afterward. Fructose and glucose were also found to be dominant sugars in the earlier stages of ripening (stages 1 and 2), with the total fructose being $12.56 \times 10^{6}$ area/g dw in stage 1 and $9.60 \times 10^{6}$ area/g $\mathrm{dw}$ in stage 2 . The total glucose in stage 1 was similar to that of fructose, while at stage 2 the amount of glucose was four times lower than that at stage 1 . At stage 5, fructose and glucose were available in similar amounts, $107.99 \times 10^{6}$ area/g $\mathrm{dw}$ and $114.41 \times 10^{6} \mathrm{area} / \mathrm{g} \mathrm{dw}$, respectively. While continuing to ripen, the level of fructose decreased by half at stage 7 , while the glucose kept rising to $140 \times 10^{6} \mathrm{area} / \mathrm{g} \mathrm{dw}$. At stages 6 and 7, altrose, mannose, and lyxose began to accumulate, with the predominance of glucose.

Beside the presence of sugars, organic acids were also found as the dominant polar metabolite compounds in the Agung Semeru plantain. Organic acids are natural compounds commonly presented in banana flesh which play an important role in determining the quality of the banana [37]. Malic acid and citric acid have been found to be the most abundant organic acids in several fruits, including bananas $[37,38]$. In this plantain, the concentrations of the dominant major acids, such as oxalic acid, malic acid, citric acid, phosphoric acid, and methylmalonic acid, changed markedly during the development and maturation. In the unripe stage (stages 1 and 2), the oxalic acid was the predominant acid, presented at the amount of $101.05 \times 10^{6} \mathrm{area} / \mathrm{g} \mathrm{dw}$ at stage 1 and $175.12 \times 10^{6}$ area/g dw at stage 2 , and it was not detected afterwards. According to Noonan and Savage [39], oxalic acid is present in several plant tissues and can impact human health, as the oxalates bind calcium and other minerals. In addition, excessive consumption of oxalic acids can cause stones to form in the urinary tract, as the acid is excreted in the urine. Meanwhile, methylmalonic acid was first found at stage 3, with far lower amounts compared to the oxalic acid, $857.11 \times 10^{3}$ area/g dw, dramatically falling by half at stage 4 and not found afterwards. Malic acid, citric acid, and phosphoric acid were the organic acids that appeared in all ripening stages. As the banana ripens, the amounts of malic acid, citric acid, and phosphoric acid increased and reached their peaks at stage 5, with approximately $20 \times 10^{6} \mathrm{area} / \mathrm{g} \mathrm{dw}$ (for malic acid and citric acid) and $6.52 \times 10^{6}$ area/g dw (for phosphoric acid), and they dropped afterwards. The results for oxalic acid, malic acid, and citric acid are in agreement with a previous study [40], which reported that oxalic acid was the predominant acid in the unripe stage of bananas and continuously declined as the banana ripened, while concentration of malic acid and citric acid increased and then started to decline when an overripe stage was reached. The decrease of the organic acids in the later stages might be due to the use of these compounds as a substrate for respiratory processes and the generation of ATP (adenosine triphosphate) during development and maturation [41].

In the early ripening stages, two compounds were clearly observed. Aspartic acid appeared in the first stage, while pyroglutamic acid was identified in stages 1 and 2 . At stage 1 , the level of aspartic acid was $2.46 \times 10^{6}$ area/g $\mathrm{dw}$, whereas the pyroglutamic acid was two times lower. 


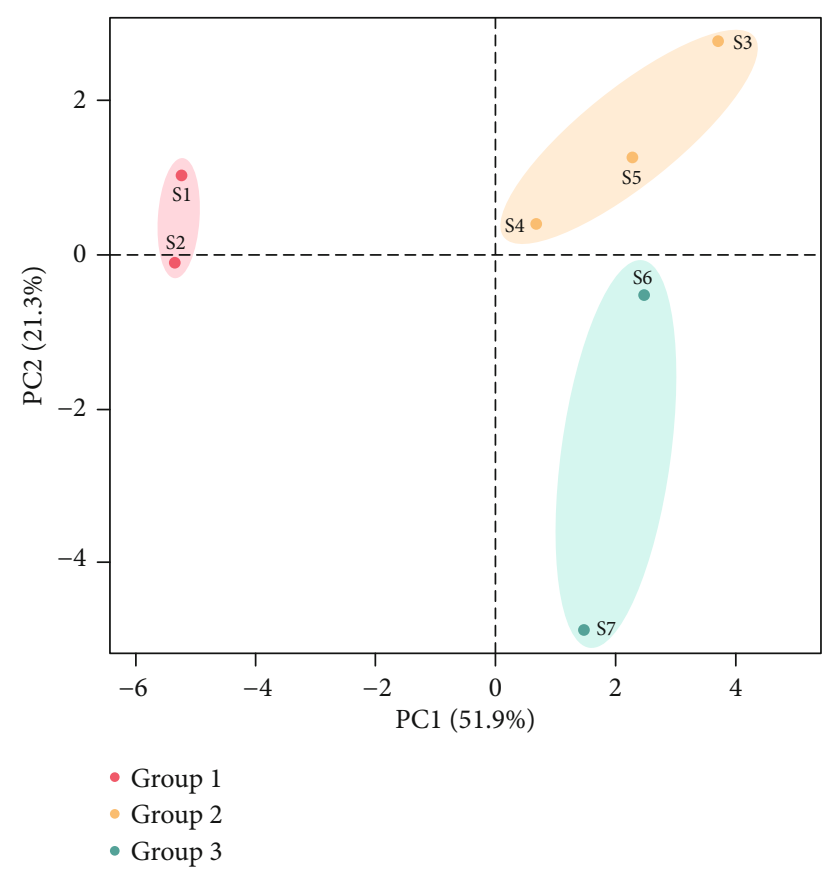

Figure 4: Principal component analysis (PCA) score plot of the identified polar metabolite compounds from seven ripening stages of the Agung Semeru plantains. Different coloured dots represent clustered stages in a group. Each stage is represented by averages of triplicates. S1: stage 1; S2: stage 2; S3: stage 3; S4: stage 4; S5: stage 5; S6: stage 6; S7: stage 7.

At stage 2, the pyroglutamic acid was decreased by half, while the aspartic acid was not detected. These findings indicate that this plantain provides a limited composition of amino acids which can only be found at the unripe stage. Furthermore, hydantoin, which is a precursor of amino acids [42], was also found in the unripe stages, at around $40 \times 10^{3}$ area/g dw in stages 1 and 2 . This is interesting as no previous investigations have revealed that this compound is present in bananas or other fruits.

The cluster patterns of the polar metabolites were observed using PCA. The PCA as part of the multivariate analysis was conducted for the set of 27 metabolite compounds, in order to investigate the differences of the metabolites among the ripening stages and to determine the close clusters for each ripening stage. Figure 4 shows the separation of seven ripening stages in PC1 and PC2, which accounted for $51.9 \%$ and $21.3 \%$ of the total variance, respectively. Stages 1 and 2 were tightly clustered together in the negative side of the $\mathrm{PC} 1$ as group 1 and were clearly separated from the other five ripening stages. This suggests closely related or identical metabolite compounds in stages 1 and 2, which might be contributed by the amino acid groups and oxalic acid. Stages 3 to 5 and stages 6 and 7 were grouped together on the positive side of the PC1, as groups 2 and 3, respectively. However, it can also be seen that the position of stage 6 was close to the cluster for group 2, which may be because the metabolite compounds of stage 6 were a transition between group 2 and stage 7 . This might be contributed by the presence of sugars and organic acids (phosphoric acid, citric acid, and malic acid), which were also predominant until stage 6 , while at stage 7 organic acids were reduced and there were new sugar groups detected, such as mannose and lyxose.

\section{Conclusions}

Evaluations of the provitamin A carotenoids and the polar metabolite compositions in the Agung Semeru banana (Musa paradisiaca $\mathrm{L}$. $\mathrm{AAB}$ ) found that there were high amounts of provitamin A carotenoids, due to the predominance of the $\alpha$-car and $\beta$-car, with organic acids and sugars as the predominant polar metabolites. Stages 1 and 5 had the highest amounts of provitamin A carotenoids, which contributed to the levels of vitamin A activity. Compared to the Cavendish type, the Agung Semeru banana provided vitamin A activity that was 60 to 90 times higher and was able to fulfil a person's daily requirements, if $150 \mathrm{~g}$ was consumed when it was in stage 1 or 5 and $300 \mathrm{~g}$ in stage 6 . Malic acid and citric acid were the predominant organic acids that were found in all ripening stages, while oxalic acid and methylmalonic acid were only present in the earlier stages. Lower levels of oxalic acid indicate a better quality of banana plantain. Moreover, sucrose, glucose, and fructose, collectively referred to as sugars, were found in all ripening stages. The sugars gradually decreased with time, except for glucose, which continued to increase and became the dominant sugar in stage 7 , accompanied by the accumulations of new sugars, mannose and lyxose. This shows that the Agung Semeru banana is a promising fruit that could be widely produced as a nutritional and energy food resource, due to its high levels of vitamin A activity and sugars.

\section{Data Availability}

All data generated or analyzed during this study are included in this published article and its supplementary material files.

\section{Conflicts of Interest}

The authors declare that there are no conflicts of interest regarding the publication of this paper.

\section{Acknowledgments}

The authors thank Marcelinus A. S. Adhiwibawa for assistance in the visualization of the data from the multivariate analysis. This research was funded by the National Competence Research Grant (grant number 061/SP2H/LT/K7/KM/2018) for financing the analysis works and the World Class Research (grant number 042/SP2H/LT-MULTI/LL7/2020) for financing the preparations of the manuscript and the English editing from the Directorate of Research and Community Services, Ministry of Research, Technology, and Higher Education of the Republic of Indonesia.

\section{Supplementary Materials}

Supplementary Table 1: carotenoid concentrations, total carotenoids, and vitamin A activity in the Agung Semeru 
plantain at all ripening stages, resolved using HPLC and spectrophotometry UV-Vis. Supplementary Table 2: polar metabolite compounds from the Agung Semeru plantain at all ripening stages, resolved by gas chromatography-mass spectrometry (GC-MS). Supplementary Figure 1: a typical separation profile of the targeted polar metabolite compounds from the Agung Semeru plantain in ripening stage 5, resolved by gas chromatography-mass spectrometry (GCMS). (Supplementary Materials)

\section{References}

[1] WHO, "Global prevalence of vitamin A deficiency in populations at risk 1995-2005," in WHO Global Database on Vitamin A Deficiency, World Health Organization, Geneva, 2009, https://apps.who.int/iris/bitstream/handle/10665/44110/9789 241598019_eng.pdf;jsessionid=B6A310475C080697036BFB 5328A86019? sequence $=1$.

[2] H. H. Conaway, P. Henning, and U. H. Lerner, "Vitamin A metabolism, action, and role in skeletal homeostasis," Endocrine Reviews, vol. 34, no. 6, pp. 766-797, 2013.

[3] M. A. Dijkhuizen, F. T. Wieringa, C. E. West, and Muherdiyantiningsih, \& Muhilal, "Concurrent micronutrient deficiencies in lactating mothers and their infants in Indonesia," The American Journal of Clinical Nutrition, vol. 73, no. 4, pp. 786-791, 2001.

[4] Atmarita, "Nutrition problems in Indonesia," in An Integrated International Seminar and Workshop on Lifestyle-Related Diseases, 2005 March, pp. 19-20, Gajah Mada University, Jogjakarta, Indonesia, 2005.

[5] J. P. Wirth, N. Petry, S. A. Tanumihardjo et al., "Vitamin A supplementation programs and country-level evidence of vitamin A deficiency," Nutrients, vol. 9, no. 3, pp. 1-18, 2017.

[6] F. Granado, B. Olmedilla, I. Blanco, E. Gil-Martinez, and E. Rojas-Hidalgo, "Variability in the intercomparison of food carotenoid content data: a user's point of view," Critical Reviews in Food Science and Nutrition, vol. 37, no. 7, pp. 621-633, 1997.

[7] S. A. Tanumihardjo, N. Palacios, and K. V. Pixley, "Pro-vitamin A carotenoid bioavailability: what really matters?," International Journal for Vitamin and Nutrition Research, vol. 80, no. 4-5, pp. 336-350, 2010.

[8] L. Englberger, I. Darnton-hill, T. Coyne, M. H. Fitzgerald, and G. C. Marks, "Carotenoid-rich bananas : a potential food source for alleviating vitamin A deficiency," Food and Nutrition Bulletin, vol. 24, no. 4, pp. 303-318, 2003.

[9] L. Englberger, R. B. H. Wills, B. Blades, L. Dufficy, J. W. Daniells, and T. Coyne, "Carotenoid content and flesh color of selected banana cultivars growing in Australia," Food and Nutrition Bulletin, vol. 27, no. 4, pp. 281-291, 2006.

[10] J. M. Holden, A. L. Eldridge, G. R. Beecher et al., "Carotenoid Content of U.S. Foods: An Update of the Database," Journal of Food Composition and Analysis, vol. 12, no. 3, pp. 169-196, 1999.

[11] M. W. Davey, E. Stals, G. Ngoh-Newilah et al., "Sampling strategies and variability in fruit pulp micronutrient contents of West and Central African bananas and plantains (Musa species)," Journal of Agricultural and Food Chemistry, vol. 55, no. 7, pp. 2633-2644, 2007.

[12] J. Paul, H. Khanna, J. Kleidon et al., "Golden bananas in the field : elevated fruit pro-vitamin A from the expression of a single banana transgene," Plant Biotechnology Journal, vol. 15, no. 4, pp. 520-532, 2017.

[13] R. V. Valmayor, S. H. Jamaluddin, B. Silayoi et al., Banana cultivar names and synonyms in Southeast Asia, International Network for the Improvement of Banana and Plantain (INIBAP) - Asia and the Pacific Office, Laguna, 2000.

[14] J. Iskandar, J. Kusmoro, M. Mubarokah, and R. Partasasmita, "Ethnobotany of banana plants (Musa x paradisiaca) of Palintang Hamlet, Cipanjalu Village, Bandung, West Java, Indonesia," Biodiversitas, vol. 19, no. 6, pp. 2059-2072, 2018.

[15] P. E. R. Prahardini, “The genetic potency of plantain agung semeru variety from Lumajang regency East Java Indonesia," Jurnal Biologi El-Hayah, vol. 1, no. 1, pp. 25-29, 2009, http:// journaldatabase.info/articles/genetic_potency_plantain_ agung_semeru.html.

[16] P. E. R. Prahardini, "Karakterisasi Varietas Unggul Pisang Mas Kirana dan Agung Semeru di Kabupaten Lumajang," Buletin Plasma Nutfah, vol. 16, no. 2, pp. 126-133, 2010, http:// ejurnal.litbang.pertanian.go.id/index.php/bpn/article/view/ 5129.

[17] Y. Rohmah, Outlook Komoditas Pisang, L. Nuryati and B. Waryanto, Eds., Kementerian Pertanian Indonesia, Jakarta, 2016.

[18] H. Juncai, H. Yaohua, H. Lixia, G. Kangquan, and T. Satake, "Classification of ripening stages of bananas based on support vector machine," International Journal of Agricultural and Biological Engineering, vol. 8, no. 6, pp. 99-103, 2015.

[19] R. Drury, S. Hortensteiner, I. Donnison, C. R. Bird, and G. B. Seymour, "Chlorophyll catabolism and gene expression in the peel of ripening banana fruits," Physiologia Plantarum, vol. 107, no. 1, pp. 32-38, 1999.

[20] P. Thomas and M. T. Janave, "Effect of temperature on chlorophyllase activity, chlorophyll degradation and carotenoids of Cavendish bananas during ripening," International Journal of Food Science \& Technology, vol. 27, no. 1, pp. 5763, 1992.

[21] B. Ekesa, D. Nabuuma, G. Blomme, and I. Van den Bergh, "Provitamin A carotenoid content of unripe and ripe banana cultivars for potential adoption in eastern Africa," Journal of Food Composition and Analysis, vol. 43, pp. 1-6, 2015.

[22] G. N. Newilah, C. Dhuique-Mayer, J. Rojas-Gonzalez, K. Tomekpe, and F. X. Etoa, "Carotenoid contents during ripening of banana hybrids and cultivars grown in Cameroon," Fruits, vol. 64, no. 4, pp. 197-206, 2009.

[23] M. N. Islam, M. Y. Imtiaz, S. S. Alam, F. Nowshad, S. A. Shadman, and M. S. Khan, "Artificial ripening on banana (Musa Spp.) samples : analyzing ripening agents and change in nutritional parameters," Cogent Food \& Agriculture, vol. 4, no. 1, pp. 1-16, 2018.

[24] P. Khawas, A. J. Das, N. Sit, L. S. Badwaik, and S. C. Deka, "Nutritional composition of culinary Musa ABB at different stages of development," American Journal of Food Science and Technology, vol. 2, no. 3, pp. 80-87, 2014.

[25] R. da Costa Nascimento, O. de Oliveira Freire, L. S. Ribeiro et al., "Ripening of bananas using Bowdichia virgilioides Kunth leaves," Scientific Reports, vol. 9, no. 1, p. 3548, 2019.

[26] J. S. Sidhu and T. A. Zafar, "Bioactive compounds in banana fruits and their health benefits," Food Quality and Safety, vol. 2, no. 4, pp. 183-188, 2018.

[27] R. H. Stover and N. W. Simmonds, "Bananas," in Tropical Agricultural Series (Third), Longman, Essex, 1987. 
[28] G. J. Septiany, W. D. R. Putri, I. N. Panca, H. Heriyanto, and A. P. D. L. Limantara, "Carotenoid analysis of ripe banana flesh and peel from three cultivars of Banana," Indonesian Journal of Natural Pigments, vol. 1, no. 2, p. 60, 2019.

[29] J. M. Kurniawan, M. M. Yusuf, S. S. Azmi et al., "Effect of drying treatments on the contents of lutein and zeaxanthin in orange- and yellow- cultivars of marigold flower and its application for lutein ester encapsulation," IOP Conference Series: Materials Science and Engineering, vol. 509, article 012060, 2019.

[30] J. Gross, Pigments in Vegetables: Chlorophylls and Carotenoids, Van Nostrand Reinhold, New York, 1991.

[31] J. Zhang, X. Wang, O. Yu et al., "Metabolic profiling of strawberry (Fragaria $\mathrm{x}$ ananassa Duch.) during fruit development and maturation," Journal of Experimental Botany, vol. 62, no. 3, pp. 1103-1118, 2011.

[32] T. F. Jorge, A. T. Mata, and C. Antonio, "Mass spectrometry as a quantitative tool in plant metabolomics," Philosophical Transactions of the Royal Society A Mathematical Physical and Engineering Sciences, vol. 374, no. 2079, p. 20150370, 2016.

[33] M. M. Wall, "Ascorbic acid, vitamin A, and mineral composition of banana (Musa sp.) and papaya (Carica papaya) cultivars grown in Hawaii," Journal of Food Composition and Analysis, vol. 19, no. 5, pp. 434-445, 2006.

[34] Institute of Medicine (US) et al., Dietary Reference Intakes for Vitamin A, Vitamin K, Arsenic, Boron, Chromium, Copper, Iodine, Iron, Manganese, Molybdenum, Nickel, Silicon, Vanadium, and Zinc, National Academies Press (U.S.), Washington, DC, USA, 2001.

[35] M. E. Arena, A. Zuleta, L. Dyner, D. Constenla, L. Ceci, and N. Curvetto, "Berberis buxifolia fruit growth and ripening: evolution in carbohydrate and organic acid contents," Scientia Horticulturae, vol. 158, pp. 52-58, 2013.

[36] T. Y. Kheng, P. Ding, and N. A. Abdul Rahman, "Determination of optimum harvest maturity and physico-chemical quality of Rastali banana (Musa AAB Rastali) during fruit ripening," Journal of the Science of Food and Agriculture, vol. 92, no. 1, pp. 171-176, 2012.

[37] S. D. T. Maduwanthi and R. A. U. J. Marapana, "Comparative study on aroma volatiles, organic acids, and sugars of Ambul banana (Musa acuminata, $\mathrm{AAB}$ ) treated with induced ripening agents," Journal of Food Quality, vol. 2019, 9 pages, 2019.

[38] M. A. Romero Rodriguez, M. L. Vazquez Oderiz, J. Lopez Hernandez, and J. Simal Lozano, "Determination of vitamin c and organic acids in various fruits by HPLC," Journal of Chromatographic Science, vol. 30, no. 11, pp. 433-437, 1992.

[39] S. C. Noonan and G. P. Savage, "Oxalate content of foods and its effect on humans," Asia Pacific Journal of Clinical Nutrition, vol. 8, no. 1, pp. 64-74, 1999.

[40] H. Wyman and J. K. Palmer, "Organic acids in the ripening banana fruit," Plant Physiology, vol. 39, no. 4, pp. 630-633, 1964.

[41] J. J. Giovannoni, "Genetic regulation of fruit development and ripening," Plant Cell, vol. 16, Supplement, pp. S170-S180, 2004.

[42] A. S. Bommarius, M. Schwarm, and K. Drauz, "Biocatalysis to amino acid-based chiral pharmaceuticals-examples and perspectives," Journal of Molecular Catalysis - B Enzymatic, vol. 5, no. 1-4, pp. 1-11, 1998. 